\title{
Fatigue in maritime transport
}

\author{
Andrea Galieriková ${ }^{1}$, Andrej Dávid ${ }^{1}$, Jarmila Sosedová ${ }^{1}$ \\ ${ }^{1}$ Department of Water Transport, University of Žilina, \\ Univerzitná 8251/1, 01026 Žilina - Slovakia
}

\begin{abstract}
The maritime system operates non-stop, by the workers who operate, sleep, eat and live 24/7 in noisy, dynamic and stressful environment. Irregular and extended shifts are not unusual for the workers aboard. The final result of the extended shifts is fatigue, represented by the symptoms such as drowsiness, irritability, reduced alertness, lack of concentration and memory, depression and headaches. Lack of sleep or rest can impair the cognitive skills, slows down the reaction times and makes it difficult to concentrate. Proving fatigue as the cause of the maritime accident can be a challenging task. So, the method of investigation the fatigue in the terms of maritime transport has to be used. This paper provides a recommendation for the process of investigation and assessing of the causal factors, such as human factor, especially the fatigue. The preventive measures how to avoid the fatigue aboard the vessel are also given.
\end{abstract}

Index Terms - fatigue, maritime, accident, incident, human.

\section{INTRODUCTION}

Shipping industry represents one of the most important elements of the global economy. According to ICCSWT (2020), more than $90 \%$ of the world's trade is carried by sea or navigable rivers. The maritime industry is a $24 / 7$ business, it's not unusual for the workers to be on call 24 hours a day or work shifts that last 12 hours and longer. Prescriptive hours of work and rest limits, set out by the IMO (International Maritime Organization) and by the ILO (International Labour Organization) are the primary fatigue risk management requirements, setting minimum standards of compliance in the international shipping industry. Current regulations allow maximum of 14 hours of work in a 24 hours period with a maximum of 72 hours of a work in a 7-day period. IMO also sets minimum rest periods that should be not less than 10 hours in any 24 hours period and 77 hours in any 7-day period. Noncompliance of the work and sleep periods usually leads to the fatigue as a causal factor of alarming number of maritime accidents (Dávid, et al. 2016). Because the staff must perform many tough tasks on board the vessels for a long working

ASEJ - Scientific Journal of Bielsko-Biala School of Finance and Law

Volume 24, No 1 (2020), 4 pages

DOI: $10.5604 / 01.3001 .0014 .1349$

Received: 23 January 2020; Accepted: 20 February 2020 periods, the job fatigue is a constant and dangerous condition in the maritime industry.

\section{FATIGUE}

Fatigue can be defined in many ways. Generally, it is described as a state of feeling tired or sleepy that results from prolonged mental or physical work, extended period of anxiety, exposure to harsh environments, or loss of sleep. The effects of fatigue are particularly dangerous in the shipping industry. The technical and specialised nature of this industry requires constant alertness and intense concentration from its workers. Fatigue is also dangerous because it affects everyone regardless of skills, knowledge and training (Interreg, 2018). It must be recognized that the ship's personnel is "captured" in their working environment. Ship's personnel spend long time living and working away from home, on a moving vessel that is liable to unpredictable environmental factors. There is also no clear separation between work and recreation on board. The limiting element is also represented by crew, composed of people from various nationalities, who are expected to live and work together for a long period of time. Galieriková (2019) claims, according to her research of the maritime accidents, that the human error represents $75 \%$ to $96 \%$ incidents in the shipping sector with the fatigue as one of the most common failure. Analysis of the maritime accidents also shows that alarming number of the human failures were the results of the errors in judgement by maritime workers, suffering from extreme fatigue. According to McCallum (1996), fatigue alone was the cause of up to $16 \%$ of casualties. Fatigue, as an element of human behavior, causes 33\% of injuries at sea (Sanquest 1996)

TABLE 1 .

MARITIME ACCIDENTS (2015 - 2019) AND CAUSAL FACTORS

\begin{tabular}{|c|c|c|c|c|c|}
\hline Year & $\mathbf{2 0 1 5}$ & $\mathbf{2 0 1 6}$ & $\mathbf{2 0 1 7}$ & $\mathbf{2 0 1 8}$ & $\mathbf{2 0 1 9}$ \\
\hline Human factor & $\begin{array}{c}30 \\
(94 \%)\end{array}$ & $\begin{array}{c}31 \\
(78 \%)\end{array}$ & $\begin{array}{c}19 \\
(86 \%)\end{array}$ & & \\
\hline Other factors & $8(25 \%)$ & $\begin{array}{c}10 \\
(25 \%)\end{array}$ & $\begin{array}{c}7 \\
(32 \%)\end{array}$ & & \\
\hline Causal factors & 38 & 41 & 26 & & \\
\hline
\end{tabular}

Regular research paper: Published 30 April 2020 Corresponding author's e-mail: galierikova@fpedas.uniza.sk; andrej.david@fpedas.uniza.sk; sosedova@fpedas.uniza.sk Copyright ( $\odot 2018$ This is an open access article distributed under the Creative Commons Attribution CC-BY-NC 4.0 License. 
TABLE 1 .

MARITIME ACCIDENTS (2015 - 2019) AND CAUSAL FACTORS

\begin{tabular}{|c|c|c|c|c|c|}
\hline Year & $\mathbf{2 0 1 5}$ & $\mathbf{2 0 1 6}$ & $\mathbf{2 0 1 7}$ & $\mathbf{2 0 1 8}$ & $\mathbf{2 0 1 9}$ \\
\hline Number of accidents & 36,0 & 35,9 & 35,8 & & \\
\hline
\end{tabular}

Galieriková, 2019

\section{FATIGUE INVESTIGATION}

Investigations of maritime accidents is based on a review of the number of marine accident reports (NTSB) and statistical data (EMSA). Based on a detailed analysis, it was assessed whether a marine accident was due to fatigue and if so, which crew member had erred and how. The research on fatigue causation was also used (Strauch, 2015). This research cites essentially fournon-medical causes of fatigue:

- deficient sleep in the hours immediately preceding event that leads to acute fatigue,

- sleep loss in the days or nights preceding the accident that can lead to chronic fatigue

- extended time awake (effects of the extended wakefulness) before the task leads to fatigue

- time zone changes or shift work that leads to the sleep disruption.

The research of a board workers fatigue includes the information about the medical condition and medication use of the workers. The basis of information also allows to determine whether the worker was fatigued, based on the documented history of quality and quantity of his or her sleep. Then, assuming the accident was based on the human error, it is necessary to determine that a fatigued master committed the error because he or she was fatigued.

Failures of comprehension or interpretation (for example) can be also attributed inexperience or inadequate training. In other words, some failures or errors can be explained by causes other than fatigue, but to determine that fatigue led to an error, hardly establishing that the worker (master) was fatigued by itself is insufficient to make such a determination if an alternative to fatigue can also cause the failure. But, if there is no alternative explanation such as inexperience or inadequate training can be applied, then these factors can be excluded as potential explanations and fatigue applied to explain the failure.

An example

The process of identifying fatigue as cause of accident can be applied to an investigation of a tanker collision. The tanker "Eagle Otome" collided on a narrow waterway once with the docked vessel and then with another one approaching it from the opposite direction. The accident occurred mainly because the conning pilot, controlling the navigation of the tanker, was somewhat late in ordering a vessel heading change that was needed to traverse an upcoming bend in the waterway. The master recognized the need for the turn late so he compensated the delay by ordering a larger heading change than is typically used (because the vessel was too close to the waterway bend that it should have been for initiating the turn). So, the master had a radio call with a crewmember of another vessel to turn at a point in time and distance that was closer to the actual waterway bend. During the turning, the vessel came too close to the waterway bank and it lost steering effectiveness as it began to shear as a result of hydrodynamic forces, associated with proximity to the bank (EMSA, 2018). Then, the collision occurred.

FIGURE 1. COLLISION OF THE EAGLE OTOME SHIIP THE STRUCTURE OF LOCAL
GOVERNMENT UNITS EXPENDITURE ON CULTURE AND NATIONAL HERITAGE PROTECTION

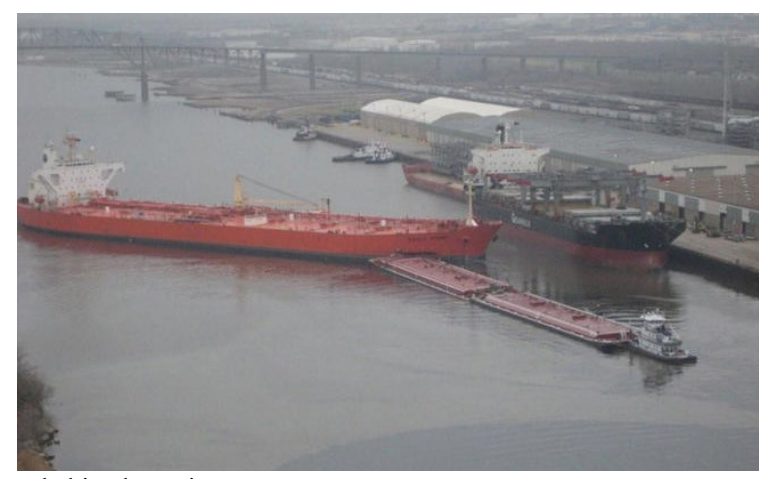

Source: thehimalayantimes.com

The master's error of being late in recognizing the necessity for and in ordering the turn is consistent with degraded cognitive performance. Despite the radio communications, the master was not able to monitor progress of the vessel and the necessity for a turn when appropriate. Difficulty in shifting attention between the tasks (from the radio communication to vessel navigation) is also consistent with degraded cognitive performance of fatigue (EMSA, 2016) The master did the right action (the turn), but this action was made too late, so it could not be performed safely.

Investigators considered all explanations of the master's error behaviour such as master's skills level, but this hypothesis was disproved. The master had had considerable experience in this position, had completed two years of training and also had served as a master for four years before the accident. Also, his performance history had been good - he had not been involved in previous incidents and he also had had no record of violations as a mariner. So, investigators identified two various sources of fatigue with the negative effect on the master's cognitive performance. The master had been diagnosed with sleep apnea (but he was not treating it), and the second reason was that two days before the accident he had worked 27 hours straight, from 7,00 through the night to 10,00 the next morning. Then he had slept from 10,15 the day before accident to 17,00 that afternoon, then again from 21,00 until he had been awakened at 2,30 upon being told to start the work. Although he had slept the day and night before accident, investigators showed that disrupted sleep patterns, had resulted in poor quality daytime sleep so his sleep had been insufficient to compensate his acute sleep loss the night before. Also, his night sleep would not have been able to compensate the sleep loss because of his being awakened at 2,30 that is also the phase of a deep sleep, so the sleep disruption can be particularly insidious (Strauch 2015). Thus, given several information about the master and his sleep/awake schedule in the days before the accident, the character of his 
errors and the quality and quantity of his previous experience, investigators had enough information to determine that the failure had been affected by the fatigue of master. This method of assessing fatigue provides systematic, objective means to determine the role of fatigue in the terms of maritime accidents (EMSA 2016).

So, according this study, method and the investigation of real maritime accident with the fatigue as main causal factor, three critical questions can be used in the future research of the maritime accidents:

was the master fatigued? - if, so:

was the master's error consistent with being fatigued? - if, so:

are there other causes of the accident from the captain?

It is enough for the first two answers to be positive during the maritime accidents and causal factors investigation. Two positive response represents absolute evidence that the mariner was fatigued at the time of the accident.

In general, if the main cause of maritime accident is the fatigue of the crew or captain, it is necessary to define the factors affecting fatigue and eliminate and give prevention measurements to eliminate the fatigue on board to a minimum.

\section{FACTORS OF FATIGUE}

The most common causes of fatigue on board are poor quality of rest, lack of sleep, stress or the excessive workload. There are many other factors as well, and each varies depending on the circumstances - crew specific factors, management factors, environmental and ship specific factors.

\section{A. Crew specific factors}

The crew specific factors are related to personal habits, lifestyle, behaviour and individual attributes. However, fatigue varies from one person to another and its effects are often dependent on the particular activity being performed. The crewspecific factors include the following:

1) Rest and sleep:

- poor quality, quantity and duration of sleep;

- sleep disorders/disturbances;

- rest breaks.

2) Biological clock/circadian rhythms:

- fear;

- monotony and boredom.

- $\quad$ workload (mental/physical);

- jet lag.

3) Health:

- diet;

- illness.

4) Ingested chemicals:

- alcohol;

- drugs (prescription and non-prescription);

- caffeine.

5) Other:

- personal problems;
- interpersonal relationships.

\section{B. Management specific factors}

These factors relate to how vessels are managed and operated. These factors can potentially increase workloadand cause stress that ultimately resulting in fatigue. These factors include:

- role offshore personnel;

- paperwork requirements;

- economics;

- $\quad$ schedules-shift, overtime, breaks;

- company culture and management style;

- rules and regulations;

- resources;

- upkeep of vessel;

- training and selection of crew (Jurkovič, Kalina 2016).

\section{Ship specific factors}

These factors include vessel design features that can affect/cause fatigue. Some vessel design features affect workload (i.e. automation, equipment reliability), some affect the crew's ability to sleep, and others affect the level of physical stress on the crew (i.e. noise, vibration, accommodation spaces etc.).

These factors include:

- vessel design;

- level of automation;

- equipment reliability;

- inspection and maintenance;

- age of vessel;

- comfort in work and accomodation spaces (Sulgan, Sosedova, 2016).

\section{Environmentally specific factors.}

Exposure to excessive levels of environmental factors, such as the temperature, humidity, excessive noise can cause of affect fatigue. Long term exposure may even cause harm to a person's health. These factors can also contribute to the disruption of sleep.

Vessel motion is also considered an environmental factor. Motion affects a person's ability to maintain physical balance. This is due to the extra energy expended to maintain balance while moving, especially during harsh water conditions. There is a direct relation between a vessel's motion and a person's ability to work. Excessive vessel movement can also cause nausea and motion sickness (Interreg 2018).

Environmental factors can also be divided into factors external to the vessel (weather conditions, vessel traffic)

\section{PREVEntion AND Mitigation OF FAtigue}

There are several steps that can be taken to prevent fatigue. Although, many of the measures reducing the fatigue are 
unfortunately beyond a single person's control (for example voyage scheduling, ship design, and work scheduling).

Following proposed steps are important in the prevention of fatigue on board vessel:

- Ensure compliance with applicable legislations (maximum hours of work or/and minimum hours of rest);

- Develop and maintain good sleep habits (such as pre-sleep routine);

- Eat regular, well-balanced meals (including fruits and vegetables, as well as meat and starches);

- Exercise regularly;

- Drink sufficient amounts of water;

- Use rested personnel for exchange of those who are working long hours on board;

- Ensure the open communication environment (e.g.by explain to crew members that it is necessary to inform supervisors when fatigue has an impact on their performance without any recriminations for such reports);

- Schedule drills with regard to minimizing the disturbance of rest/sleep period;

- Schedule potentially hazardous tasks for daytime hours;

- Mix up tasks to break up monotony work that requires high physical or mental demand with low-demand tasks;

- Emphasis the relationship between work and rest periods;

- Establish shipboard practices for dealing with fatigue incidents and learning from the past.

\section{CONCLUSIONS}

The shipping industry is a $24 / 7$ business with the extended shifts as a common thing for maritime workers. It's not unusual for board staff and other offshore workers to work 24 hours a day or work shifts that last 12 hours or longer. These unusual extended work hours represent lack of rest and sleep that their minds and bodies require. The result is worker fatigue. Fatigue can impair a person's cognitive skills, slowing down their reaction times, making it difficult to concentrate, and adversely affect decision making skills with high probability of an accident formation.

The process of investigating fatigue in the terms of maritime accidents consists of the analyzing of the history of the hours the worker (master, crew, shore officer, etc.) spent performing particular jobs in the 24 hours before the accident. Then worker's sleep/wake schedule each day in the weeks preceding an accident are investigated, and also, the medical conditions and medication use of the "error" workers on board vessel must be considered.

If the error is consistent with fatigue, investigators must rule out other potentially competing alternative explanations to find out the answer if he or she was fatigued.

So, the complex investigations of fatigue as a causal factor of maritime accident can improve safety in the shipping industry and ensure more efficient on-board performance.

\section{REFERENCES}

Dávid, A., Piala, P., Stupalo, V. (2016). Cargo containerisation and its impact on the development of maritime transport. In: 3rd International Conference on Traffic and Transport Engineering (ICTTE). Belgrade, Serbia 2016; p. 306-311.

European Maritime Safety Agency (EMSA). (2018). Analysis on Marine Casualties and Incidents Involving Fishing Vessels. 42 pp.

Galieriková, A. (2019) The human factor and maritime safety. heaj13th International Scientific Conference on Sustainable, Modern and Safe Transport (TRANSCOM 2019), High Tatras, Novy Smokovec - Grand Hotel Bellevue, Slovak Republic, May 29-31, 2019

International Chamber of Shipping: Shipping and World Trade. (2020). Shipping and world trade. Available at: http://www.ics-shipping.org/shippingfacts/shipping-and-world-trade

Interreg: Human Resource Management and Social Responsibility on Board Managerial Level. (2018). Module I - Principles and Good Practices in Shipboard Human Resource Management. Compendium.

Jurkovič, M., Kalina, T. (2016). Water transport - the challenge for the automotive industry in Slovakia In: Communications: scientific letters of the University of Žilina. - ISSN 1335-4205. - Vol. 18, no. 2. pp. 26-29.

McCallum, M. C., et al. (1996). Procedures for Investigating and Reporting Human Factors and Fatigue Contributions to Marine Casualties. Report No. CG-D-09-97. Seattle: Battelle Seattle Research Center.

National Transportation Safety Board (NTSB). (2020). Investigations. Marine accident reports. Available at: https://www.ntsb.gov/investigations/accidentreports/pages/marine.aspx

Sanquest, T. F., et al. (1996) Fatigue and Alertness in Merchant Marine Personnel: A Field Study of Work and Sleep Patterns. Report No. CG-D-06-97. Seattle: Battelle Seattle Research Center

Sulgan, M., Sosedova, J.. (2016) Rationalization of internal transport operation in the intermodal transport terminal. Communications: scientific letters of the University of Žilina. - ISSN 1335-4205. - Vol. 18, no. 2

Strauch, B. (2015) Investigating fatigue in marine accident investigations. 6th International Conference on Applied Human Factors and Ergonomics (AHFE 2015) and the Affiliated Conferences, National Transportation Safety Board1, 490 L'Enfant Pl, SW, Washington, DC. 